\title{
Innovative dentists wanted
}

\section{New cover series celebrates teeth in}

\section{literature}

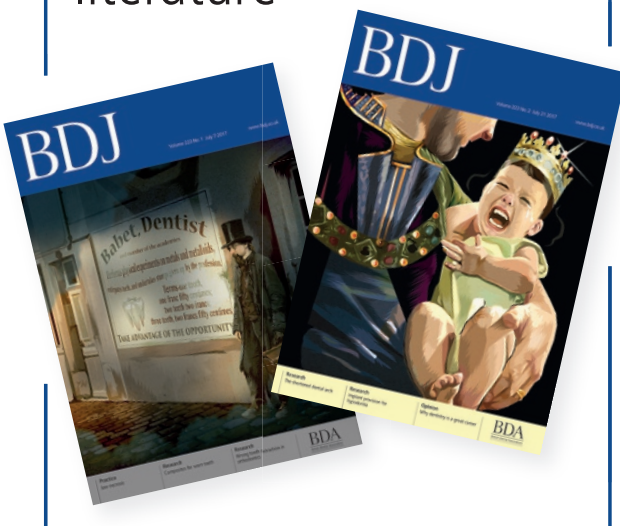

The cover series for the current volume of the $B D J$ (Volume 223) is based on dentistry in literature.

Each of the 12 covers for this volume will illustrate instances where dentistry or teeth feature in literature. A wide range of sources were considered by the editorial and production team: from well known 'great works' to more obscure authors and from older classics to modern novels.

The first cover in the series, which was published on 7 July 2017, depicts Babet, the 'dental practitioner' from Victor Hugo's Les Misérables, the French historical novel first published in 1862 .

The second cover [this issue] features Richard III, who in Shakespeare's play is said to have been born with teeth and 'camest to bite the world'.

Artist Matthew Laznicka has produced each of the 12 cover illustrations for the $B D J$.

Melissa Cassem, Art Editor for the BDJ Portfolio, said: 'Once we had decided on the 12 literary excerpts for the covers, the difficult part was deciding on how we could visualise each of them.

'We shortlisted a few illustrators, all of whom had book illustrations within their folio, but we loved Matthew's classic style, which has a painterly feel, despite being digital.'

Future covers will depict scenes relating to Bram Stoker's Dracula, Agatha Christie's One, Two, Buckle My Shoe, Zadie Smith's White Teeth, Siegfried Sassoon's Memoirs of an Infantry Officer, Hans Christian Andersen's Auntie toothache, Geoffrey Chaucer's The Wife of Bath and more.
The Clinical Entrepreneurial Programme is now open to all dentists who are developing or aspire to embrace clinical innovations or enterprises in the profession.

Managed jointly by NHS England, Health Education England and endorsed by the Chief Dental Officer for England, the scheme was developed over more than a year of intensive work with entrepreneurial clinicians, academic leaders and industry partners.

The Clinical Entrepreneur Programme includes:

- Mentoring and coaching scheme - from an acclaimed international faculty including commercial, financial, clinical, academic, managerial, and public sector leaders and achievers

- Customer matching - establishing relationships with providers/customers to deliver pre-commercial procurement opportunities

- Possible entrepreneurial placements/ internships - with industry, charities, social enterprises and public sector organisations with both partner funded and self-funding options
- Time for entrepreneurial activity such as less than full-time, annualised job planning, time out from clinical duties.

The curriculum covers all aspects of setting up and running a small business, including attracting investors, applying for funding, and ensuring appropriate corporate governance. A dedicated programme in how to build a start-up - and how to operate in this highly-charged environment - is delivered as a series of 'Pitstop' educational events.

The application process runs from 10 July to 9 August 2017. Interviews will be held on 30 and 31 August and 1 September. The programme will commence in autumn 2017.

To apply for the clinical entrepreneur training programme, complete the application form on NHS England's Innovation web portal at http://www.innovation.england.nhs. $\mathrm{uk} /$ clinical-entrepreneur.

To find out more about the overall programme see https://www.england.nhs.uk/ ourwork/innovation/clinical-entrepreneur/.

\section{Dental hospitals form new Association}

Dental hospitals across the UK and Ireland have reorganised into the Association of Dental Hospitals, which works to provide a voice for dental hospitals. The Association comprises 18 dental hospitals or academic clinical facilities, all of which deliver the mixture of clinical service, teaching and research that is fundamental to the future of dental healthcare.

By reorganising into this new structure, dental hospitals will be able to combine their expertise to meet the challenges of an evolving profession.

The Association of Dental Hospitals has now come under the same umbrella as the Dental Schools Council and Association of UK University Hospitals, among other organisations. These connections will provide a stronger voice for dental hospitals and will facilitate closer working, both between dental hospitals and with partners across other sectors and areas of healthcare.

Dental hospitals will continue to work with their dental school partners to help ensure the future of the workforce by providing high-quality training for dental students. The Association of Dental Hospitals aims to foster closer relationships with partner organisations with the ultimate goal of improving patient care.

Dr Avril Macpherson, Chair of the Association of Dental Hospitals and Clinical Director at Liverpool University Dental Hospital, said: 'The Association of Dental Hospitals provides an opportunity for colleagues to learn from each other. One of the ways we have been doing this for the past five years has been through a Clinical Effectiveness meeting, held annually in Manchester, where problems and solutions in clinical practice at dental hospitals are shared. We are delighted to have the means to cooperate at a national level and make use of the membership's significant breadth of knowledge'.

The Association of Dental Hospitals is steered by an Executive Committee, which is elected according to its Constitution. Member organisations are represented by their clinical director and the senior nonclinical manager of the dental hospital. www.dentalhospitals.org.uk 